\title{
PENGARUH KONSENTRASI EKSTRAK DAUN TEMBAKAU SEBAGAI INHIBITOR PADA TULANGAN BETON BERTULANG
}

\author{
Nurtalia Barmawi ${ }^{1}$, Mufti Amir Sultan ${ }^{* 2}$ dan Muhmmad Yunus Hi Abbas ${ }^{3}$ \\ 1 Mahasiswa, Program Sarjana, Program Studi Teknik Sipil, Fakultas Teknik, Universitas \\ Khairun \\ 2 Dosen, Program Studi Teknik Sipil, Fakultas Teknik, Universitas Khairun \\ 3 Dosen, Program Studi Teknik Elektro, Fakultas Teknik, Universitas Khairun \\ *Korespondensi : muftiasltn@unkhair.ac.id
}

\begin{abstract}
Reinforced concrete structures that are destroyed due to corrosion attacks need serious handling. One method of preventing corrosion is by using an inhibitor. In this study, the inhibitors used were tobacco leaf extract inhibitors with variations of $0 \%, 4 \%$ and $8 \%$. The method used to analyze the corrosion rate that occurs is the weight loss method. Tests carried out by providing electricity to the test object using a voltage of $5 \mathrm{~V}$. The results showed that the influence of the addition of tobacco extract inhibitors at concentrations of $4 \%$ and $8 \%$ was able to reduce the density of anodic and cathodic currents which resulted in a reduced corrosion rate in steel reinforcement. This proves that tobacco extract can be used as a green corrosion inhibitor because it effectively decreases the corrosion rate.
\end{abstract}

Keywords: Tobacco Leaf Extract, Inhibitor, Corrosion, Sea Water

\section{PENDAHULUAN}

Perkembangan

pembangunan

infrastruktur sipil dewasa sangat berkembang seiring dengan perkembangan penduduk. Peningkatan jumlah penduduk tentunya harus diimbangi dengan penyediaan infrastruktur sipil untuk menopang kehidupan masyarakat. Perkembangan infrastruktur tidak terkecuali pada wilayah pesisir dimana sebagian besar wilayah Indonesia secara umum dan khususnya Maluku Utara pada wilayah ini. Pilihan utama dalam pembangunan infrastruktur adalah dengan menggunakan beton, penggunaan beton secara umum menjadi piliahan karena mempunyai banyak keuntungan diantaranya gampang dibentuk sesuai dengan keinginan perencana. Namun beton mempnyai kelemahan yaitu kemampuan dalam menerima beban tarik relatif kecil dibandingkan dengan kekuatan tekannya. Untuk mengatasi kelemahan ini maka digunakan material baja sebagai tulangan yang berfungsi untuk menahan gaya tarik. Problem yang dihadapi oleh baja adalah korosi apalagi infrastrukur tersebut berada pada wilayah pesisir atau pada lingkungan yang agresif.

Korosi adalah kerusakan atau degradasi logam akibat reaksi redoks antara suatu logam dengan berbagai zat di lingkungannya yang menghasilkan senyawa-senyawa yang tidak dikehendaki. Dalam bahasa sehari-hari, korosi disebut perkaratan. Contoh korosi yang paling lazim adalah perkaratan besi. Pencegahan korosi bergantung pada jenis atau tipe korosi yang terjadi pada material terkorosi. Ada beberapa cara pencegahan korosi. Salah satu metode yang terus dikaji saat ini adalah pencegahan korosi dengan menggunakan penghambat korosi atau inhibitor alami.

Perkembangan pembangunan infrastruktur sipil dewasa sangat berkembang seiring dengan perkembangan penduduk. Peningkatan jumlah penduduk tentunya harus diimbangi dengan penyediaan infrastruktur sipil untuk menopang kehidupan masyarakat. Perkembangan infrastruktur tidak terkecuali pada wilayah pesisir dimana sebagian besar wilayah Indonesia secara umum dan khususnya 
Maluku Utara pada wilayah ini. Pilihan utama dalam pembangunan infrastruktur adalah dengan menggunakan beton, penggunaan beton secara umum menjadi piliahan karena mempunyai banyak keuntungan diantaranya gampang dibentuk sesuai dengan keinginan perencana. Namun beton mempnyai kelemahan yaitu kemampuan dalam menerima beban tarik relatif kecil dibandingkan dengan kekuatan tekannya. Untuk mengatasi kelemahan ini maka digunakan material baja sebagai tulangan yang berfungsi untuk menahan gaya tarik. Problem yang dihadapi oleh baja adalah korosi apalagi infrastrukur tersebut berada pada wilayah pesisir atau pada lingkungan yang agresif.

Hal ini menjadikan penelitian ini penting untuk pengendalian korosi pada infrastruktur sebagai upaya mitigasi korosi dan meningkatkan life time dari struktur pada struktur beton bertulang seperti yang telah dilakukan sebelumnya namun menggunakan abu sekam padi [1]

\section{TINJAUAN PUSTAKA}

Korosi adalah kerusakan atau degradasi logam akibat reaksi redoks antara suatu logam dengan berbagai zat di lingkungannya yang menghasilkan senyawa-senyawa yang tidak dikehendaki. Dalam bahasa sehari-hari, korosi disebut perkaratan. Contoh korosi yang paling lazim adalah perkaratan besi. Pencegahan korosi bergantung pada jenis atau tipe korosi yang terjadi pada material terkorosi. Ada beberapa cara pencegahan korosi. Salah satu metode yang terus dikaji saat ini adalah pencegahan korosi dengan menggunakan penghambat korosi atau inhibitor alami.

Penggunaan inhibitor alami yang berasal dari tumbuhan terbukti dapat menghambat laju korosi pada besi seperti penggunaan daun teh [2][3][4][5]. Pemanfaatan tumbuhan lain seperti daun manggis[6], penggunaan tannin yang diperoleh dari ekstrak daun jambu[7] dan daun salam[8] penggunaan daun gambir[9][10]. Pemanfaatan bubuk azadirachta indica (neem) dan ekstrak lidah buaya[11]. Penggunaan getah pinus dan ekstrak limbah kulit jeruk[5]. Pemanfaatan limbah puntung rokok dan tembakau[12][13][14][15]. Ekstrak daun papaya digunakan dapat menjadi inhibitor pada tulangan baja[16][17]. Penambahan inhibitor ekstrak tembakau dengan metode weight loss pada konsentrasi $4 \%$ dan $8 \%$ mampu menurunkan rapat arus anodik dan katodik yang mengakibatkan laju korosi pada baja tulangan [18]. Inhibitor organik alami terbukti efektif dari perspektif ekologis dan lingkungan dan dapat memainkan peran utama dibandingkan inhibitor sintetis. Di masa mendatang inhibitor organik alami akan lebih diminati mengingat produk tanaman muncul sebagai penghambat korosi yang efektif karena ramah lingkungan, ketersediaannya yang mudah, sifatnya yang murah dan tidak beracun[5]. Penggunaan inhibitor alami akan terus digunakan untuk pencegahan korosi di masa depan dengan modifikasi lebih lanjut. Perbaikan masa depan harus menggabungkan jenis inhibitor dengan sifat adsorpsi yang sangat baik dan mekanisme anodik atau katodik untuk mencapai inhibitor alam dengan kinerja yang paling baik[19].

Tabel 1. Konstanta Perhitungan Laju Korosi

\begin{tabular}{|c|c|}
\hline $\begin{array}{c}\text { Satuan Laju Korosi / } \\
\text { Corrosion Rate }\end{array}$ & Konstanta \\
\hline Mils per year (mpy) & $3,45 \times 10^{6}$ \\
\hline Inches per year (ipy) & $3,45 \times 10^{3}$ \\
\hline Inches per month (ipm) & $2,87 \times 10^{2}$ \\
\hline Milimeters per year $(\mathrm{mm} / \mathrm{y})$ & $8,76 \times 10^{4}$ \\
\hline Micrometer per year $(\mu \mathrm{m} / \mathrm{y})$ & $8,76 \times 10^{7}$ \\
\hline Picometres per second (pm/s) & $2,78 \times 10^{6}$ \\
\hline $\begin{array}{l}\text { Grams per square metre per } \\
\text { hour }\left(\mathrm{g} / \mathrm{m}^{2} . \mathrm{h}\right)\end{array}$ & $1,00 \times 10^{4} \times \mathrm{DA}$ \\
\hline $\begin{array}{l}\text { Milligrams per square } \\
\text { decimeter per day (mdd) }\end{array}$ & $2,40 \times 10^{6} \times \mathrm{DA}$ \\
\hline $\begin{array}{l}\text { Micrograms per square metre } \\
\text { per second }\left(\mu \mathrm{g} / \mathrm{m}^{2} . \mathrm{s}\right)\end{array}$ & $2,78 \times 10^{6} \times \mathrm{DA}$ \\
\hline
\end{tabular}
Sumber: ASTM [20]

Analisa laju korosi dengan menggunakan Metode weight loss atau kehilangan berat. Prinsip dari metode ini adalah dengan menghitung banyaknya material yang hilang atau kehilangan berat setelah dilakukan pengujian rendaman sesuai dengan standar ASTM G 31. Dengan menghitung massa logam yang telah dibersihkan dari oksida dan massa tersebut dinyatakan sebagai massa awal lalu dilakukan pada suatu lingkungan yang korosif seperti pada air laut selama waktu tertentu. Setelah itu dilakukan penghitungan massa kembali dari suatu logam setelah dibersihkan logam tersebut dari hasil korosi yang terbentuk dan massa tersebut dinyatakan sebagai massa akhir. Dengan mengambil beberapa data seperti luas permukaan yang terendam, waktu 
perendaman dan massa jenis logam yang di uji maka dihasilkan suatu laju korosi.

Persamaan laju korosi dapat ditunjukkan pada persamaan berikut :

$$
C R=\frac{K w}{D A T}
$$

dimana,

$$
\begin{array}{ll}
\mathrm{CR} & =\text { laju korosi } \\
\mathrm{K} & =\text { konstanta (sesuai Tabel 1), } \\
\mathrm{T} & =\text { time of exposure, } \\
\mathrm{A} & =\text { luas permukaan yang direndam }\left(\mathrm{cm}^{2}\right), \\
\mathrm{W} & =\text { kehilangan berat }(\mathrm{gram}), \\
\mathrm{D} & =\text { density }\left(\mathrm{gram} / \mathrm{cm}^{3}\right)
\end{array}
$$

Persamaan efesiensi inhibitor ditunjukkan pada persamaan berikut :

Efesiensi Inhibitor $=(\mathrm{Xa}-\mathrm{Xb}): \mathrm{Xa}$

dimana

$\mathrm{Xa}=$ Laju korosi tanpa inhibitor (mpy)

$\mathrm{Xb}=$ Laju korosi dengan inhibitor (mpy)

\section{METODE PENELITIAN}

Metode penelitian dengan menggunakan benda uji berbentuk silinder dengan dimensi 300 x 101,6 mm. Mutu beton yang digunakan $25 \mathrm{MPa}$. Tulangan ditanam ke dalam beton sepanjang $200 \mathrm{~mm}$. Diameter tulangan beton yang digunakan $10 \mathrm{~mm}$ tulangan polos. Pada proses pengecoran air dicampur dengan ekstrak tembakau pada $4 \%$ dan $8 \%$. Sebagai benda uji kontrol digunaka benda uji tanpa menggunakan Sebagai benda uji kontrol digunaka benda uji tanpa menggunakan ekstrak tembakau. Material pembentuk beton agregat kasar dari quarry Togafo, agregat halus digunakan pasir laut dan pasir gunung dengan pencampur air laut dan air tawar. Pada proses pencampuran ditambahkan ekstrak tembakau diperoleh dengan metode maserasi. Tahapan pembuatan ektrak tembakau seperti dijelaskan sebagai berikut :

a. Mengeringkan sampel daun tembakau sebanyak 2500 gram dalam suhu kamar selama 3 hari untuk menghilangkan kadar air.

b. Menghaluskan sampel yang telah kering dengan blender untuk mempermudah dan memaksimalkan proses ekstraksi.

c. Mengekstrak daun tembakau menggunakan metode maserasi.

d. Melakukan metode maserasi dengan memasukkan daun tembakau yang telah halus ke dalam wadah kemudian di isi etanol 70\% dan di rendam selama 5 hari.

e. Menyaring hasil perendaman menggunakan kertas saring hingga memperoleh filtrat.

f. Kemudian menguapkan filtrat dari hasil proses tersebut menggunakan alat penguap putar vakum (rotary evaporator) dengan kecepatan $200 \mathrm{rpm}$ dan suhu $50^{\circ} \mathrm{C}$ hingga menghasilkan ekstrak pekat, seperti ditunjukkan pada Gambar 1.

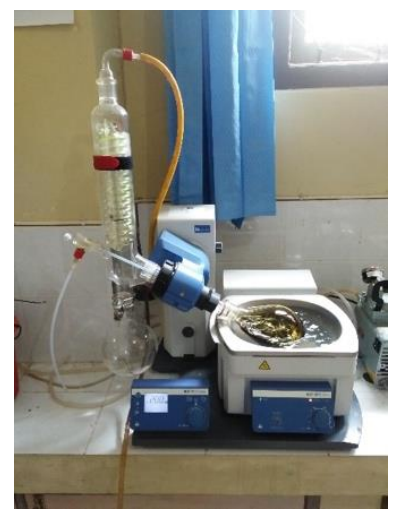

Gambar 1. Proses Penguapan Filtrat

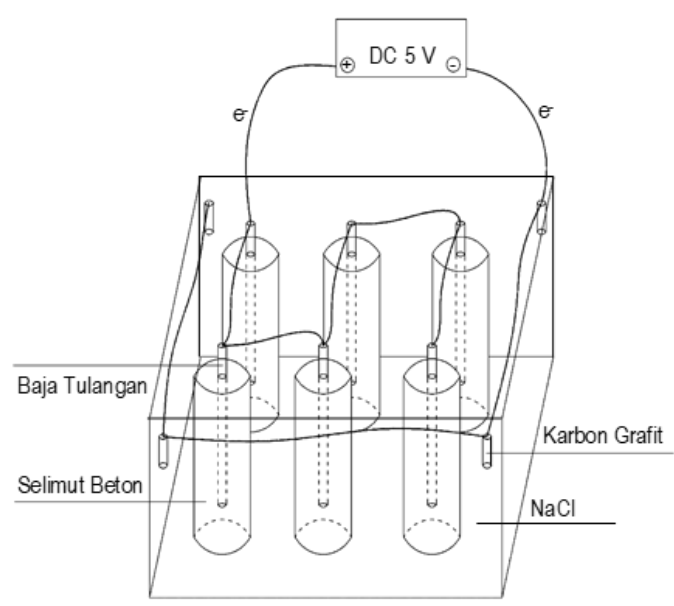

Gambar 2. Pengujian Korosi dengan Arus Listrik

Pengujian korosi dilakukan dengan memberikan arus listrik dan tegangan pada benda uji pada rentang waktu tertentu. Proses pengujian ini mengacu pada ASTM C 31-72. Adapun tata cara pembuatan benda uji sebagai berikut :

a. Bak perendaman dan isi larutan $\mathrm{NaCl}$ (air laut) dengan salinitas 3,5\% dengan tinggi air $200 \mathrm{~mm}$. 
b. Masukkan benda uji kedalam bak perendaan yang sudah berisi larutan $\mathrm{NaCl}$.

c. Pasangkan kabel pada baja tulangan dan karbon grafit kemudian hubungkan ke power supply. Pada pengujian ini rangkaian disusun secara paralel dengan karbon grafit sebagai katodanya dan baja tulangan sebagai anodanya.

d. Setting power supply dengan potensial dikisarkan 5 volt selama 3 hari. Mekanisme pengujian seperti pada Gambar 2.

\section{HASIL DAN PEMBAHASAN \\ 4.1 Pengamatan Visual}

Pasca pengujian korosi dengan menggunakan arus listrik terjadi perubahan secara visual pada beton dan tulanga baja, perubahan secara visual pada beton dan tulangan baja seperti pada Gambar 3

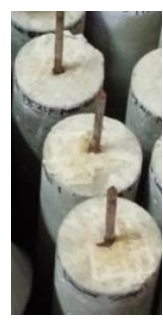

Sebelum pengujian

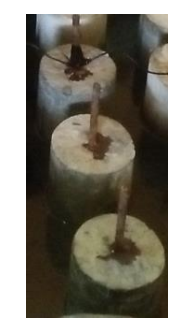

Setelah pengujian

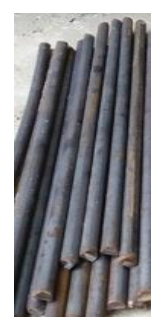

Sebelum pengujian

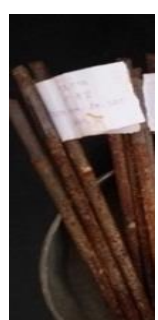

Setelah pengujian $\begin{array}{cl}\text { Gambar 3. } & \text { Visualisasi Perubahan Pada } \\ & \text { Permukaan Beton dan Baja } \\ & \text { Tulangan }\end{array}$

Berdasarkan Gambar 3 dapat dilihat bahwa muncul karat pada permukaan beton yang berasal dari tulangan yang tertanam dalam beton, begitu pula baja tulangan terjadi karat setelah pengujian dengan mengalirkan arus listrik, tulangan dapat dilihat setelah benda uji beton dibongkar.

\subsection{Laju Korosi}

Hasil perhitungan laju korosi dengan persamaan (1), dimana nilai $\mathrm{K}$ dari Tabel 1 sebesar 1,00 x $104 \times \mathrm{D}$, T selama 744 jam, luas permukaan $\mathrm{A}=0,0095770 \mathrm{~m}^{2}$ kehilangan berat w 1,5 gr. Dari data eksperimen diperoleh laju korosi CR sebesar 2105,1781 gr/m $/ \mathrm{m}^{2} \mathrm{H}$. Hasil laju korosi keselurahan benda uji dengan variasi inhibitor ditunjukkan pada Gambar 4.

Ekstrak tembakau dapat digolongkan sebagai inhibitor yang dapat menghambat korosi pada tulangan beton. Pengaruh dari penambahan konsentrasi inhibitor terhadap laju korosi dari pengujian yang telah dilakukan, terdapat perubahan dalam hal ini penurunan laju korosi pada tulangan beton sebelum dan sesudah di tambahkan ekstrak tembakau, seperti pada Gambar 4.

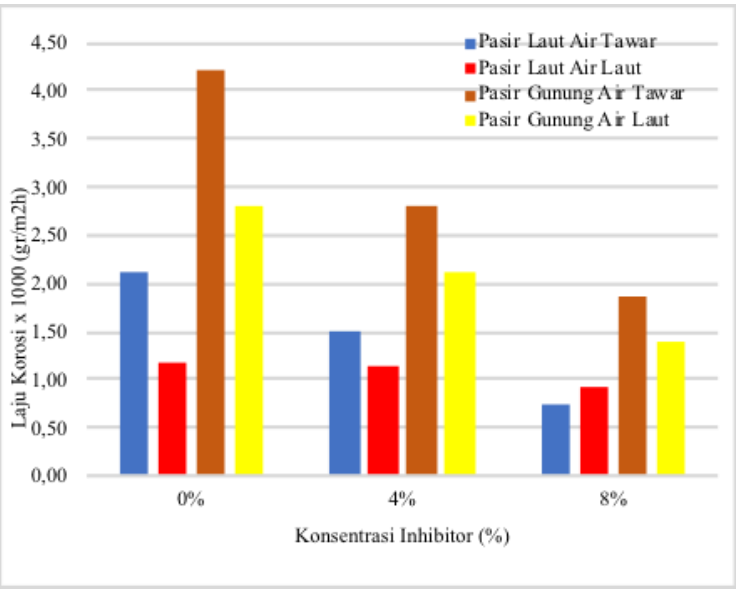

Gambar 4. Grafik Hubungan Konsentrasi Inhibitor dengan Laju Korosi

Berdasarkan Gambar 4 dapat dijelaskan bahwa dengan penambahan ekstrak tembakau kedalam campuran beton mampu menurunkan laju korosi pada ke empat jenis benda uji dengan penurunan laju korosi terendah pada benda uji pasir laut dan air laut yaitu sebesar $20 \%$. Untuk ketiga benda uji mengalami penurunan laju korosi $>50 \%$.

\subsection{Efesiensi Inhibitor}

Perhitungan efesiensi inhibitor dengan menggunakan persamaan (2), dimana laju korosi tanpa inhibitor $2806,90 \mathrm{gr} / \mathrm{m}^{2} . \mathrm{H}$ dan laju korosi dengan inhibitor 2105,18 gr/ $\mathrm{m}^{2} . \mathrm{H}$. Dari data tersebut diperoleh efesiensi korosi $25 \%$. Hasil efesiensi inhibitor pada semua benda uji ditunjukkan pada Gambar 5.

Berdasarkan data pada Gambar 5 dapat disimpulkan bahwa penambahan inhibitor ekstrak tembakau dapat menurunkan rapat arus anodik dan katodik yang mengakibatkan laju korosi, semakin tinggi konsentrasi inhibitor yang diberikan maka semakin tinggi pula efesiensi inhibitor tersebut. Rata-rata variasi campuran beton memiliki efesiensi inhibitor yang baik yakni $50 \%$ pada setiap konsentrasi inhibitor $8 \%$ ekstrak tembakau. Penurunan optimum laju korosi dengan efesiensi tertinggi 
terjadi pada penambahan inhibitor $8 \%$ ekstrak tembakau dengan variasi campuran pasir Togafo (biasa) air tawar yaitu sebesar 55,56\%. Secara umum, hasil penelitian menunjukkan bahwa peningkatan konsentrasi inhibitor ekstrak tembakau dapat menurunkan arus korosi baja tulangan yang menyebabkan efesiensi semakin tinggi.

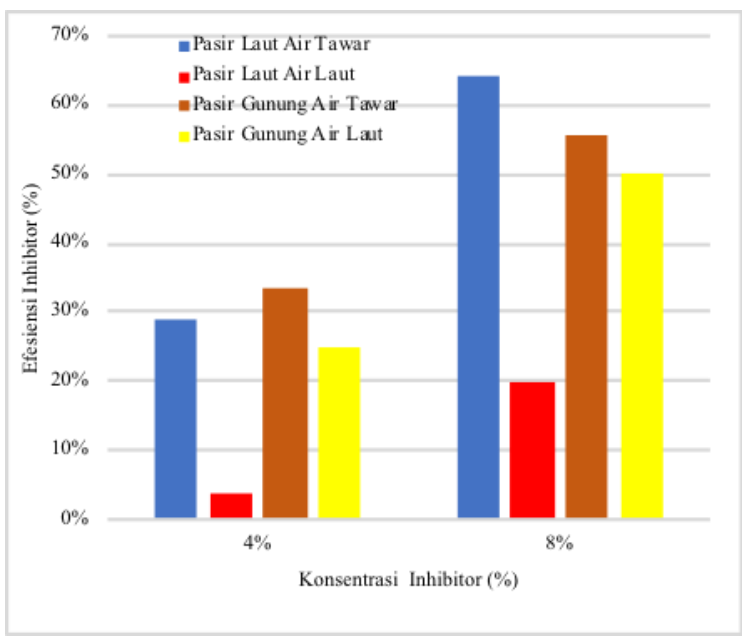

Gambar 5. Grafik Efesiensi Inhibitor dengan Konsentrasi Inhibitor

\section{KESIMPULAN}

Pengaruh penambahan inhibitor ekstrak tembakau pada konsentrasi $4 \%$ dan $8 \%$ mampu menurunkan rapat arus anodik dan katodik yang mengakibatkan laju korosi pada baja tulangan, semakin tinggi konsentrasi inhibitor yang diberikan maka semakin tinggi pula efesiensi inhibitor tersebut. Hal ini membuktikan bahwa ekstrak tembakau dapat dimanfaatkan sebagai green corrosion inhibitor karena efektif menurunkan laju korosi.

\section{UCAPAN TERIMA KASIH}

Ucapan terima kasih disampaikan kepada Universitas Khairun yang telah membiayai penelitian ini melalui skema Penelitian Kompetitif Unggulan Perguruan Tinggi Tahun Anggaran 2019.

\section{DAFTAR PUSTAKA}

[1] S. H. Usman, M. A. Sultan, and M. Y. H. Abbas, "Penggunaan Abu Sekam Padi Sebagai Inhibitor Alami Pada Tulangan Beton Bertulang," SIPILsains, vol. 9, no. 18, pp. 47-58, 2019.
[2] Y. Ludiana and S. Handani, "Pengaruh Konsentrasi Inhibitor Ekstrak Daun Teh ( Camelia sinensis ) Terhadap Laju Korosi Baja KArbon Schedule 40 Grade B ERW," J. Fis. Unand, vol. 1, no. 1, pp. 12-18, 2012.

[3] D. Sari, S. Handani, and Y. Yetri, "Pengendalian Laju Korosi Baja St-37 Dalam Medium Asam Klorida Dan Natrium Klorida Menggunakan Inhibitor Ekstrak Daun Teh (Camelia Sinensis)," J. Fis. Unand, vol. 2, no. 3, pp. 204-211, 2013.

[4] Y. Yetri, D. M. Sari, and S. Handani, "Effisiensi Inhibisi Inhibitor Ekstrak Daun Teh (Camelia sinensis) Terhadap Baja St-37 dalam Medium Asam dan Garam," $J$. Katalisator, vol. 1, no. 1, pp. 1-10, 2016.

[5] G. Haryono, B. Sugiarto, and H. Farid, "Ekstrak Bahan Alam sebagai Inhibitor Korosi," in Seminar Nasional Teknik Kimia "Kejuangan" Pengembangan Teknologi Kimia untuk Pengolahan Sumber Daya Alam Indonesia Yogyakarta, 2010, pp. 1-6.

[6] L. B. Turnip, S. Handani, and S. Mulyadi, "Pengaruh Penambahan Inhibitor Ekstrak Kulit Manggis Terhadap Penurunan Laju Korosi Baja ST-37," J. Fis. Unand, vol. 4, no. 2, pp. 144-149, 2015.

[7] F. Ali, D. Saputri, and R. F. Nugroho, "Pengaruh Waktu Perendaman Dan Konsentrasi Ektstra Daun Jambu Biji (Psidium guajava, Linn) Sebagai Inhibitor Terhadap Laju Korosi Baja SS 304 Dalam Larutan Garam Dan Asam," Tek. Kim., vol. 20, no. 1, pp. 28-37, 2014.

[8] E. Yufita and D. Fitriana, "Pengendalian Laju Korosi Pada Baja Plat Hitam a36 Dalam Medium Korosif Menggunakan Inhibitor Ekstrak Daun Salam Control of Corrosion Rate on a36 Black Plate Steel in Corrosive Medium Using Salam Leaf," J. Aceh Phys. Soc., vol. 7, no. 2, pp. 67-71, 2018.

[9] E. Murti, S. Handani, and Y. Yetri, "Pengendalian Laju Korosi Pada Baja API 5L Grade B N Menggunakan Ekstrak Daun Gambir (Uncaria Gambir Roxb)," J. Fis. Unand, vol. 5, no. 2, pp. 172-178, 2016.

[10] S. R. Irianty and M. P. Sembiring, "Pengaruh Konsentrasi Ekstrak Daun Gambir Dengan Pelarut Etanol-Air Terhadap Laju Korosi Besi Pada Air Laut," J. Ris. Kim., vol. 5, no. 2, pp. 165-174, 2012.

[11] C. Lisha, M. Rajalingam, and S. George, "Corrosion Resistance Of Reinforced Concrete With Green Corrosion Inhibitors," Int. J. Eng. Sci. Invent. Res. Dev., vol. 3, no. 11, pp. 687-691, 2017.

[12] R. N. Ahmadi, S. Oediyani, and G. 
Priyotomo, "Pengaruh Penambahan Inhibitor Ekstrak Tembakau Terhadap Laju Korosi Internal Pipa Baja API 5L X - 52 Pada Artificial Brine Water Dengan Injeksi Gas CO 2," J. Furn., vol. 2, no. 1, pp. 1-8, 2016.

[13] B. P. Andeka, B. Suharto, and A. T. S. H. Haji, "Efektifitas Limbah Puntung Rokok Sebagai Bahan Inhibitor Korosi Pada Paku Besi Dalam Media Air Tawar," J. Sumberd. Alam dan Lingkung., vol. 2, no. 2, pp. 1-6, 2015.

[14] H. Istiqlaliyah and P. Candrama, "Pemanfaatan limbah putung rokok, daun tembakau , dan kopi sebagai inhibitor besi," J. Mesin Nusant., vol. 1, no. 1, pp. 1-9, 2018.

[15] D. Drastinawati and S. R. Irianty, "Pemanfaatan Ekstrak Nikotin Limbah Puntung Rokok sebagai Inhibitor Korosi," Teknobiologi, vol. 4, no. 2, pp. 91-97, 2013.

[16] S. Handani and M. S. Elta, "Pengaruh Inhibitor Ekstrak Daun Pepaya Terhadap Korosi Baja Karbon Schedule 40 Grade B Erw Dalam Medium Air Laut dan Air
Tawar," J. Ris. Kim., vol. 8, no. 2, pp. 175-179, 2015.

[17] R. S. Irianty and D. Khairat, "Ekstrak Daun Pepaya sebagai Inhibitor Korosi pada Baja AISI 4140 dalam Medium Air Laut," J. Teknobiologi, vol. IV, no. 2, pp. 77-82, 2013.

[18] M. A. Sultan, A. Gaus, K. A. Rakhman, and N. Barmawi, "Penggunaan Ekstrak Tembakau Sebagai Inhibitor Pada Beton Bertulang Menggunakan Pasir Laut dan Air Laut," Teras J., vol. 10, no. 1, pp. 17-26, 2020.

[19] Y. P. Asmara, T. Kurniawan, A. G. E. Sutjipto, and J. Jafar, "Application of plants extracts as green corrosion inhibitors for steel in concrete - A review," Indones. J. Sci. Technol., vol. 3, no. 2, pp. 158-170, 2018.

[20] ASTM G1-90, "Standard Practice for Preparing, Cleaning, and Evaluation Corrosion Test Specimens," Astm, p. 8, 2003. 